\section{Spring awakening planned for Mars rover Spirit}

Your ill-timed 'obituary', in

News, for the Mars rover Spirit (Nature 463, 600; 2010) brings to mind Mark Twain's saying that reports of his death had been exaggerated. Spirit is alive and well - albeit with limited mobility - and is still returning scientific data from Mars more than six years after landing.

As the Martian winter advances in the months ahead, we expect Spirit to hibernate (not die) by cutting off its communication with Earth and conserving electrical power. Once the Martian spring arrives, we expect Spirit to re-awaken and start doing science once again.

We plan to continue using Spirit's wheels to try to reposition the vehicle. But even if very little motion is achieved, we can still carry out an extended science campaign, including tracking Spirit's radio signal to find out whether the core of Mars is molten or solid.

The day will come when an obituary can be written that lauds Spirit's scientific accomplishments. But that day may not arrive for some time yet. Steve Squyres Mars Exploration Rover Project, Space Sciences Building, Cornell University, Ithaca, New York 14853, USA e-mail:squyres@astro.cornell.edu

\section{Esaki diode is still a radio star, half a century on}

An FM transistor radio owned by one of us (L. E.) since the early 1960 s still works beautifully. Reasoning that this was testament to the performance of its single Esaki diode, we tested the effects of storage on some of these germanium devices made in 1960.

The Esaki diode (L. Esaki Phys. Rev. 109, 603-604; 1958) was the first quantum-electron

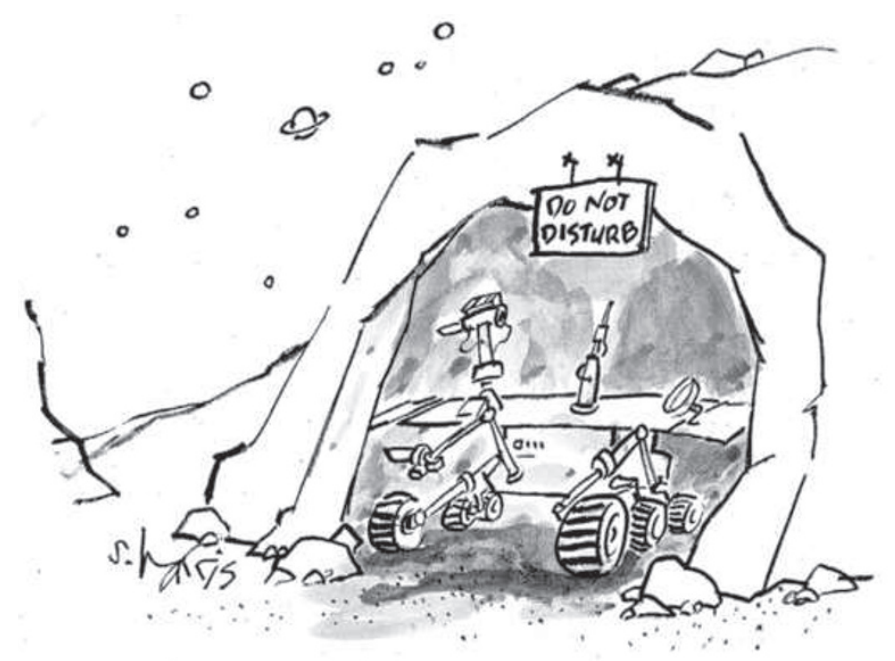

device. Unlike the mechanism that powers most semiconductor devices, current flows through the diode as a result of quantummechanical electron tunnelling across a potential barrier.

Semiconductor transport devices are extremely stable, so their shelf-life should be infinite if they are stored at room temperature. But the Esaki diode's tunnel current is very sensitive to its enormous built-in electric field in the junction region (E. Spenke Electronic Semiconductors 232; McGraw-Hill, 1958), which could affect its long-term performance.

As the most likely indicator of any small structural changes in the device, we re-measured the peak current in 20 devices and discovered that it had fallen by an average of just 3.3\% over 50 years, corresponding to a junction widening of only $0.25 \%$.

This very tiny shift in electronic characteristics is probably down to inbuilt impurities and imperfections within the structure. A gratifying confirmation of the diode's longevity, nonetheless.

Leo Esaki The Science and Technology Promotion Foundation of Ibaraki, Tsukuba 305-0032, and Yokohama College of Pharmacy, Japan e-mail: leoesaki@epochal.or.jp Yasuhiko Arakawa, Masatoshi Kitamura Institute for Nano Quantum Information Electronics, The University of Tokyo, Komaba, Meguro 153-8505, Japan

\section{Foundations could allocate money more productively}

Could the huge grant-giving community in the United States be made more effective? This question needs addressing now, while both the economy and grant giving are down.

The Foundation Center, in New York, estimates that the 75,000 US foundations gave away $\$ 45.5$ billion in 2008 - a drop of more than $20 \%$ from 2007. Small family foundations have to reduce spending when their investment portfolios are down, but it is also common practice for even large foundations to cut back substantially.

As the grants manager of a small family foundation in New York City, I believe that there's no good excuse for this. When the economy tanks, if big foundations need to dig into capital rather than limit their spending to their legal $5 \%$ obligation - often covered by the tax-free income on their investments - then they should. Non-profit money generates jobs and purchases just as for-profit spending does, and government money.

Another widespread problem is that many grant-giving foundations won't accept unsolicited grant proposals from universities and other non-profit organizations, even though they have a duty to support them. Instead, they shop around for the organizations that seem to suit their goals best and then solicit proposals from them.

For example, of the 74 grantgiving foundations supporting diabetes research in the United States, only half accept unsolicited grant proposals, according to the Foundation Center's national database. It's worse in cancer research, with only 121 of 276 grant-giving foundations accepting unsolicited proposals.

Foundations based in California and New York were responsible for $30 \%$ of all grant giving in 2007 . Among the 40 richest foundations in those states, roughly one-third - who gave away more than $\$ 1.4$ billion in 2007 - lock their doors to grant-seekers they do not know. Here in New York City, Mayor Bloomberg's \$1.5-billion foundation is but one example of an organization that refuses unsolicited proposals.

Huge foundations that give away tens of millions of dollars annually need to reconsider their presumptions that they can consistently find their own way to the most worthy projects. They can't.

So, yes, there are ways in which the US grant-giving community could be more effective. More foundations should spend more than their minimum obligation, particularly when times are tough. And all the larger foundations should review unsolicited proposals, to enhance their effectiveness.

Ingrid Eisenstadter 40 Park Avenue, New York, New York 10016, USA e-mail: ingrid.e@earthlink.net

Contributions to Correspondence may be submitted to

correspondence@nature. com. Please see the Guide to

Authors at http://go.nature.com/ cMCHno. Science publishing issues that may be of interest to authors are regularly featured at our blog Nautilus (http://blogs. nature.com/nautilus), where we welcome comments and debate. 